\title{
Moral Disagreement in Anglican - Roman Catholic Relations
}

\author{
Oliver O'Donovan \\ Professor Emeritus, Christian Ethics and Practical Theology, Faculty of \\ Divinity, New College, University of Edinburgh, Edinburgh, UK \\ Honorary Professor, University of St Andrews, St Andrews, UK \\ oliver.odonovan@ed.ac.uk
}

\begin{abstract}
The belief that the Anglican and Roman Catholic churches were divided by moral disagreements came to prominence in the early 1980 os and affected the direction of ecumenical dialogue. But no moral disagreements go back to the Reformation era, and the perception of moral difference has undergone many changes since that time, especially reflecting differences of social and political setting. A moral agreement or disagreement is difficult to chart with precision. It is not embodied in a formulation of moral doctrine, since moral reason functions on two planes, that of evaluative description and that of deliberation and decision. Disagreement is phenomenologically present as offence, which has its own dynamic of expansion. Addressing offence, a task involving lay, theological and episcopal contributions, is the primary way in which moral agreement has to be sought and defended.
\end{abstract}

\section{Keywords}

ecumenism - moral teaching - Anglicanism - Roman Catholic Church - ARCIC moral reason

In March 1982 the Vatican's Congregation for the Doctrine of the Faith (hereinafter CDF), in its 'Observations' on the Final Report of the Anglican - Roman Catholic International Commission (hereinafter ARCIC), noted that 'moral teaching' should be given an 'important place' among the remaining 'points 
which constitute an obstacle to unity.' To the best of my knowledge this was the first official suggestion that moral teaching did constitute an obstacle to unity. The 1966 Common Declaration of Pope Paul vi and Archbishop of Canterbury Michael Ramsey, from which the dialogue had originated, identified for study not only 'theological matters' but also 'matters of practical difficulty felt on either side.' ${ }^{2}$ But these matters were understood to be difficulties of conflicting church discipline on such issues as admission to Holy Communion, and mixed marriages, not disagreements in what the two churches taught their faithful about living the Christian life. But by 1982 the implication that the two communions were divided morally passed as conventional wisdom. Raising moral teaching for ARCIC's agenda was not an idiosyncrasy of the CDF, for the topic had been proposed to Rome by national Anglican - Roman Catholic dialogues. However, the conventional wisdom is open to question, partly from history, partly from the logic of moral thought. It is a more complicated matter than it might appear to be to say either that there are or that there are not areas of moral disagreement between our two traditions. But moral disagreements always pose a potential danger. The question is a practical one: How we are to recognise the danger when it arises, and address it?

To understand why it seemed so evident in 1982 that there were these disagreements, we need to keep in mind two background features of the period. First, there was was the severe shock to the Western churches of the universal and largely spontaneous abandonment by Western nations of the legal restraints on abortion. This seemed a profoundly new and disturbing development, more so perhaps, than any other moral issue, however celebrated, that has arisen since. For it was not just one more erosion of the failing Christian purchase on the culture of Europe and America, like Sunday trading or restraints on the freedom of religious schools, but a rejection of what had been assumed to be a solid natural-law intuition of reverence for human life, supposedly a basic achievement of civilisation that commanded the agreement of all people of good will. Among the churches, especially the Protestant churches, this development was divisive in the highest degree, though just what the division was about remained quite elusive. Few Christians at the time, of whatever disposition, had any enthusiasm for the increasing use of abortion as a contraceptive practice, and though there could be arguments among Christians as to whether the unborn child was a person and just what a person was, and there could be different views on precisely what grounds, if any, might justify the termination of a pregnancy, these differences were always far behind what the changing law had actually

$1 A A S \operatorname{lxxiv}(1982)$ 1062-1074. iarccum.org/doc/?d=661.

2 iarccum.org/doc/?d=20. 
come to permit. One might have expected the speedy emergence of a common front to the effect that whatever might or might not be conceived in good conscience, what was in fact conceived was clearly not in good conscience. That never happened, and the reason was that the arguments quickly drifted from the presenting challenge of abortion to the more familiar and more imponderable question of whether culture-affirmative attitudes ought to preponderate over culture-critical ones. It became a war between the Optimists and the Pessimists, between those who thought there was the best should be made of the new situation, and those who thought themselves brought into a status confessionis. And while no Christian body could naturally claim a monopoly of optimists or pessimists, the churches showed a tendency, natural enough in a community suddenly caught off guard, to redefine themselves around the new issue. Two new forces were then at work to encourage a new sense of distance. First, as the churches tried to overcome the disturbances that they experienced in themselves with the time-honoured mantra, 'We don't have those hangups here!', each projected on to the other those worries that they could not admit to having themselves, Protestants pretending that only Roman Catholics had difficulties with abortion, Roman Catholics crediting Protestants with an eagerness to accommodate encroaching nihilism. Secondly, the pursuit of self-redefinition brought other issues back into play as analogies with the new issue. That is how it came about, for instance, that contraception and abortion, two wholly different questions, came to some Christian minds, including educated minds, to seem virtually indistinguishable.

The second background feature was an internal argument that became very sharp within Roman Catholic Moral Theology, a body of teachers and thinkers to which the Anglican world has no precise equivalent. The Vatican Council had asked for 'special care' to be given to the development of Moral Theology, the teaching of which was to be 'more nourished on the doctrine of Holy Scripture', and to display 'the lofty calling of believers in Christ and their obligation to bear fruit in love for the life of the world'. ${ }^{3}$ Within and beyond the formal boundaries of Moral Theology this appeal was heard with a ready will and answered in a variety of ways. Roman Catholic Ethics, traditionally rather a single-track science, began to take on new forms, as New Testament hermeneutics, as ecclesiology, as moral philosophy, Kantian, phenomenological or analytic. Interest in Thomas Aquinas' ethics enjoyed an ecumenically-based revival under the new banner of 'virtue-ethics'. Some Catholic Ethics, including much that was thought of as 'liberal', sought to renew the idea of Natural Law; other Catholic Ethics, including much that was thought of as

3 Optatum Totius 16. 
'conservative', sought to relegate Natural Law to the fringes - Balthasar offered a striking example of this. ${ }^{4}$ If this efflorescence of new approaches had one element in common, it was the hope of disentangling moral discussion from the quasi-legal framework that marked the traditional approach, a late survival of the medieval and Renaissance concept of law as the comprehensive form of the will of God. But barely had the summons been sounded and the response begun, when the old style made a prominent reappearance in Pope Paul VI's Encyclical Humanae Vitae.

It is hard to overstate the level of anxiety that this Encyclical produced in Roman Catholic Moral Theology. On what should have been, and under the surface continued to be, a wide-ranging and diverse exploration of new resources for Christian moral thought, there was superimposed a binary confrontation of loyalism and opposition. Opposition coalesced around the view that when it came to discerning Christian moral judgments appropriate to the age, the church's highest teaching office had a function very different, and less decisive, than in defining doctrine. Moral reason and theoretical reason were not the same thing. The kind of propositional agreement that underpinned the doctrinal unity of the church was not to be looked for in moral matters. It was a measure of the difficulty of the times that polarisation made it difficult to see how wide a range of interpretations this thesis itself allowed. No one, I believe, wanted to question the claim that a unified Christian church must have a consistent and recognisable moral witness, somehow defined. The question was how you defined it. Some, following Kantian lines, held that it could not consist in a distinctive moral proposition, only a more profound and energising commitment. The church, then, had no teaching function in morality, except, perhaps, with children and catechumens, but its exhortatory function was all the more important. This proposition, dramatic in its implications for the teaching office, tended to distract attention away from other less highly pointed ways of describing the difference between doctrinal and moral unity. If primary moral propositions are not, as such, susceptible of disagreement, or if moral propositions derive from doctrinal ones, disagreements on moral matters may indeed arise, but the priority for unity must still lie with doctrine, and the points at issue must be viewed as secondary and derivative, to be handled within their context. Inconclusive and frustrating as these debates were at the

4 Especially in his 'Nine Propositions on Christian Ethics', included in J. Ratzinger et al., Principles of Christian Morality, trans. G. Harrison (San Francisco, CA: Ignatius Press, 1986). For a fuller discussion of this text see my article, 'Christ the Categorical Imperative', in George Westhaver and Rebekah Vince (eds), Christ Unabridged: Knowing and Loving the Son of Man (London sCM Press, 2020), pp. 234-244. 
time, they brought to the surface a range of questions of undoubted importance with necessary implications for ecumenical moral agreement. ${ }^{5}$

In 1984 the second ARCIC was charged, among other things, with reporting on moral disagreements, and ten years later it did so in a short document called Life in Christ. ${ }^{6}$ Its approach was broad-brush. It argued that though disagreements 'in certain areas of practical and pastoral judgment' had arisen, they did not stand comparison with the fundamental community of moral conviction that disciples of Christ share within the church. It sought to discourage the exaggeration of differences with strong historical and situational components to them, and wrote of 'disproportionate emphasis' laid on some disagreements, blurring the common Christian commitment, which could 'provoke a sense of alienation'. As I went public with my disappointment at this document at the time of its publication, I am glad to acknowledge now that it displayed a good measure of common sense. It was probably as positive a contribution as was open to a body on which only a few members had specialist interests in Ethics. The reason I found it frustrating was that I thought a critical opportunity had been missed to address in detail the specific disagreements that were most commonly talked about. The trend to self-redefinition continued alarmingly; large claims about the extent of moral disagreement were put in circulation and listened to respectfully. A diocesan bishop of the Church of England, Chair of its Board for Social Responsibility (that body, now deceased, to which the Church of England had been indebted for most of its more thoughtful contributions to contemporary moral issues) published a popular book called So Near And Yet So Far! identifying eight moral issues on which Lambeth and Rome were, he thought, substantially disagreed. ${ }^{7}$ Of these, several were matters on which the Anglican Churches had said nothing at all; on others it was not clear that disagreements were over more than fine print. I thought, together with one or two estimable Roman Catholic moral theologians, that a careful comparative account of claims that the churches had made could prove a closer affinity than was generally supposed, and could help put those galloping disagreements back in their box.

5 For the more radical of the positions described here, cf. Josef Fuchs, Christian Morality: The Word becomes Flesh (Washington, DC: Georgetown University Press, 1987). For a less radical position, though still on these general lines, cf. Bruno Schüller, Wholly Human: Essays on the Theory and Language of Morality (Washington, DC: Georgetown University Press, 1986).

6 iarccum.org/doc/?d=14.

7 Hugh Montefiore, So Near and Yet So Far! (London: SCM Press, 1986). For the state of affairs as I perceived it in the late 1980 s see my article 'Moral Disagreement as an Ecumenical Issue', Studies in Christian Ethics 1 (1988), pp. 5-19. 
That Life in Christ had a rather muted impact was due less to its own strengths and weaknesses, let alone my criticisms, than to the timing of its appearance. It was pre-empted a few months earlier by the publication of Pope John-Paul II's Encyclical on moral questions, Veritatis Splendor, a document as ready to grasp nettles as Life in Christ had sought to avoid grasping them. ${ }^{8}$ Though in no way conceived as an ecumenical document, the Encyclical's publication proved of great ecumenical interest, at least in the English-speaking world. It found a warm reception among many Protestant Ethicists, including Anglicans, while the reaction of Roman Catholic Moral Theologians was cool at best, sometimes resembling that of a dog whose tail has been trodden on. Particularly memorable, if idiosyncratic, was the complaint of the distinguished Redemptorist, Fr. Bernhard Häring, that reading the text had induced long-lasting seizures of the brain, which threatened to remove him from the Church on earth to the Church in Heaven. ${ }^{9}$ One thing became clear, at any rate: the popular assumption of a persisting gulf between an absolutist scholastic Catholic Moral Theology and a relativist Neo-Kantian Protestant Ethics no longer corresponded in any way to reality.

To understand the reaction of the Catholic Moral Theologians one need only recall the already agitated state in which the document found them. It was hardly surprising that they would not welcome a second major papal intervention into their concerns, even one so evidently different in style, approach and aim. Protestants, unconscious of the politics and inclined to read the Pope more as a colleague than an authority, appreciated especially those aspects of John-Paul's outlook which he derived from his early studies in Max Scheler, a figure whose strong Augustinianism and rejection of Kantian formalism chimed perfectly with the mood of Protestant Ethics at the time. To them the document was all the more congenial for its focus not on presenting moral issues but on larger and more theoretical contentions about the nature of freedom and conscience, topics of discussion on which they were already deeply engaged. Roman Catholic and Protestant readers sometimes seemed to approach the text from opposite ends, the wise serpents looking first at the closing section on the church to see where the shoe might pinch, the innocent doves beginning at the beginning, and finding themselves charmed by the Pope's determination to put first things first, framing morality within

8 The document in English together with contemporary opinions: John Wilkins (ed.), Understanding Veritatis Splendor (London: SPCK, 1994). For a recent re-evaluation of its significance, see my 'Person and Conscience: Augustinian strands in John-Paul's Ethics', Roczniki Teologiczne lxvi(3) (2019), pp. 17-31.

9 Wilkins, Understanding Veritatis Splendor, p. 9. 
an evangelical narrative. Twenty-five years later the document and its author are still controversial - sometimes for reasons that have little to do with Pope John-Paul's thought. In the long twilight of his papacy he came to seem a very conservative figure. But in the first fifteen years he had been as determined to reconfigure the Church's moral teaching as to preserve it. Already by 1993 he had reconciled the tradition to 'gradualism', had found an accommodation with some aspirations of Latin American Liberation Theology, and in the Catholic Catechism had produced a summary of biblically founded Christian moral teaching, obviously cut from the same cloth as any comparable Protestant document would be. Among the various approaches to putting flesh and blood on the Council's call for a renewal of moral theology John Paul's was by no means the least adventurous.

I

But we must leave recent history to set our question against the longer background of Protestant and Roman Catholic difference. And here there is one striking observation to begin from: no moral disagreement between Anglicans and Roman Catholics goes back to the Reformation era. Whatever the longer term implications of the doctrinal differences of the sixteenth century, there was no direct corollary for the respective moral doctrines of the two communions. Of course, Anglicans and Roman Catholics constantly accused one another, during and after the Reformation, of a wide range of moral obliquities. But these charges were laid against the background of a moral law supposed to be very well understood on both sides. The era of Reformation was a voluntarist age, when it was believed that men did wrong because their hearts were evil, not because they were mistaken and not because they profoundly disagreed.

It is true that moral faults were traced back to doctrinal error. The Protestant doctrine of grace, as interpreted by Catholics, and the Catholic doctrine of papal powers, as interpreted by Protestants, seemed sufficient explanation for the sadly demoralised state in which each claimed to find the other. Yet these explanations only explained why the moral law was not observed. The idea of 'disagreement' on morality lay more or less out of reach in the sixteenth century. We should note, however, one especially interesting case where theological disagreement led quickly to moral disagreement. Sixteenth century Protestants, denying the place of marriage in sacramental doctrine, treated the indissolubility of marriage as a requirement of evangelical law, or sometimes natural law, subject to exception on grounds decisively stipulated, as 
they saw it, by Jesus and Paul. Catholics, following Augustine's sacramental logic, saw the indissolubility of Christian marriage as an ontological reality. From these different points of departure there arose different practices over the termination of marriage. But to this disagreement the Church of England was not directly party, since, notwithstanding the tragi-comic entanglement of the English Reformation with King Henry viII's divorces, it did not follow the general Protestant line on divorce. It had planned to do so in the projected but interrupted Canon Law Reform of Edward vi's reign, but by the time of James I, when Canon Law was finally settled, appetite for that change had disappeared. So the English church stayed with the Augustinian doctrine until the second half of the nineteenth century, when new currents in the wider Anglican Communion made the question controversial once again. ${ }^{10}$ Only at the end of the twentieth century did the Church of England finally settle, after much self-questioning, on a variant of the Protestant approach. ${ }^{11}$

Two distinct impulses in the seventeenth century acted as midwives for the idea of moral disagreement. One was the increasing encounter through the colonial enterprise of Christian and non-Christian cultures. The other was the popularisation in grammar schools of the late Renaissance classical education, which made thinking lay people aware of the variety of moral doctrines in pre-Christian antiquity, and suggested that in their own day, too, one could be an Epicurean or a Stoic. Yet the discovery took some time to permeate the culture, and what strikes us most about the moral discourse of the seventeenth century, a high water mark for Moral Theology in some respects, is how common to Catholic and Protestant worlds were the idioms of what came to be called 'casuistry', detailed analyses of dilemmas of conduct understood as an aspect of the pastoral task of the ordained ministry. Later something of a hate-object among Protestant polemicists, the casuistic idiom was universal in the century of odium theologicum, encountering serious criticisism only from a Roman Catholic thinker, the great Jansenist, Blaise Pascal. ${ }^{12}$

From the beginning of the eighteenth century, however, prevailing styles of moral enquiry diverged quite sharply. The Protestant world (and Anglicans with it) adopted new lay styles of moral thinking and writing, at one level literary, written for general cultural entertainment, at another philosophical,

10 For further detail see my 'Moral Disagreement as an Ecumenical Issue'.

11 See Marriage: A Teaching Document from the House of Bishops of the Church of England (Westminster: Church House Publishing, 1999).

12 In his Lettres Provinciales. 
aiming at theoretical sophistication. ${ }^{13}$ Moral Philosophy, as a self-contained discipline without immediate theological obligations, became a new ideal. The role of the church as an institutional source of moral instruction fell into the background except insofar as the Universities could still be seen as a tenuous extension of the church. Catholic Moral Theology sustained itself in the face of this European and North American trend, largely owing to the sacrament of penance and the structural role of Moral Theology in its support. And from that point on, despite attempts to reintegrate Ethics into Protestant Theology (especially associated with F. D. E. Schleiermacher in the early nineteenth century), the difference of styles remained very marked. Protestant Ethics attending by preference to philosophical and theological foundations, avoided specific moral prescriptions; Catholic Ethics continued to explore detailed perplexities of conduct. When in the wake of the traumatic conflicts of the revolutionary age the Catholic Church sought to strengthen its confessional identity, this difference of style was open to sinister interpretation. Protestant polemicists were quick to associate the differences with doctrinal stances over justification.

One conclusion we may draw from the parallel histories of Western Christian moral thought is that differences could look like moral disagreement when in fact they were shadows cast by different ecclesiological and political settings. The Reformation era did not dispute about morality, but it did dispute about ecclesiology, and therefore also about political theology. In the eighteenth century regnant models of social and educational organisation diverged considerably. Protestants and Anglicans became more committed to the model of Christian secularity: parliaments, Universities, schools, all increasingly free of clerical control, giving voice, it was thought - sometimes plausibly - to informed lay Christian understanding. Not until the nineteenth century did Protestants begin to be anxious that lay Christian culture so constructed might produce, and be in peril from, the collapse of the ideal of Christendom. The Catholic world, especially in Southern Europe, having formerly known much greater ecclesiastical involvement in cultural institutions, came to experience the clash with an anti-Christian Enlightenment earlier and more violently.

But again, the path towards separate social developments was neither consistent nor final. Protestant and Catholic social assumptions did not run in

13 In the British Isles the pioneers at the outset of the eighteenth century were Shaftesbury for the philosophical strand, Steele and Addison for the literary. Such a work as Pope's Essay on Man had perfectly serious pretensions of moral instruction, both literary and philosophical. In Europe we find antecedents much earlier, stimulated, perhaps, by the livelier philosophical environment. Schottel's Ethica (1669) was a pioneer of moral philosophical teaching. 
straight lines after 1564, but evolved contextually from one phase of history to the next, and since much of their history was on a single continent, they tended to evolve in conscious mutual reaction or imitation. When sixteenth century Protestant polemicists fulminated over the morality of a church that maintained licensed brothels in the Holy City, they were certainly not defenders of any ideal of secularity. They were champions of a clerically-led Christian social revolution which had little room for the secular logic of the Papal States. But as Protestantism became more identified with the secular, the complaint was reversed: the Catholic idea of moral order was a repressive clerical idealism. In Catholic attitudes similar transformations can be observed: the political theology of the Catholic monarchies had astonishingly Erastian features, and gave little hint of the Catholic social theory that was to emerge in the post-revolutionary era. What are we to conclude from such paradoxes? Not, I believe, that the positions taken on such topics and later superseded were merely opportunistic or self-deceived. They were, as was quite appropriate, contextually determined, passing moments in the working out of deeper convictions which, to a great extent, Catholics and Protestants held in common. That is why each party proved at different points capable of learning from the experiences of the other.

The history alone is enough to suggest that true moral agreement and disagreement do not lie on the surface of events. Like wisdom they have to be searched for. And as with wisdom we must ask, where? It is a question by no means peculiar to Anglicans and Roman Catholics. Moral agreement is, as such, an elusive concept. We necessarily hope for it, and we necessarily fear moral disagreement. That hope and that fear are inseparable from our basic determination as social and rational beings. It would be intolerably counter-intuitive, then, to suggest that agreement and disagreement were purely chimerical, occurring nowhere. Yet what constitutes agreement is much more difficult to state with clarity in the case of moral attitudes than it is in the case of doctrines and theories. Doctrinal agreements are locatable in propositions. If scientists 'agree with' Heisenberg's uncertainty-principle then any authoritative statement of that principle will constitute the matter of the agreement. Agreements are likely to have consequences that follow fairly transparently by logical argument. Those who agree on Heisenberg's uncertainty-principle are going to agree on a range of conclusions drawn from it. It is no different in theology. Of course, theologians are careful to insist that agreed propositions are not 
an end in themselves, but are only as 'true' as they are 'proved true' in the life of faith, but agreed doctrinal propositions do, nevertheless, identify the faith which is to be lived, and generate a range of conclusions on which agreement will follow from agreement on the primary propositions. Moral propositions, on the other hand, important as they may be for moral understanding, are in a less determinate relation to the implications that they generate. Imagine two people who agree on Thomas Aquinas' doctrine that justice includes retributive, distributive and social elements, and then discover that they do not agree on a whole range of implications: on whether retributive justice implies or excludes capital punishment, on whether distributive justice implies or excludes progressive taxation, on whether social justice implies or excludes the restriction of voting rights to adults or those who citizenship or residence requirements. They may ask themselves: do we, after all, agree on what we thought we agreed on? The answer is that they do, but that agreement on a formulation of that kind does not have the same necessary implications as agreement on a doctrinal or theoretical formulation. The direction of moral reasoning is inductive, not deductive; we grasp moral principles as we seek to organise and direct moral experience, but we cannot infer moral experience from the moral principles that we have grasped. That is the force of the point made in different ways by many Roman Catholic moralists in the nineteen seventies and eighties: moral reason and theoretical reason do not provide identical kinds of agreement.

The best way to conceive the difference is to imagine moral reason as operating on two planes: one of moral evaluation and description, the other of practical decision. If we want to establish a true account of a matter of fact, however complex, we can range all the elements proper to its description alongside one another, sorting out their internal relations - this is cause, this is effect; this is objective observation, this is subjective perception, and so on - but all the time aiming to form a comprehensive view. But in moral reason such a view of a practical situation is not the goal, only a step on the way to the goal. The goal is to transfer our view, however complete or incomplete it may be, onto the plane of decision and action, to determine a course of action and life that will follow coherently from it. Where theoretical reason gazes widely over land and sea, practical reason must direct our steps precisely from the quay into the boat. It must correlate the real with the practicable. On both sides of that correlation there are judgments to be made: judgments of reflection on the one hand, judgments of deliberation on the other. It is possible to find agreement on all the reflective judgments on a situation, and to disagree on the deliberative judgments; to agree, for example, that an injustice has been done and on the description on that injustice, and yet to disagree on how the injustice is to 
be remedied. For the correlation of planes is not a deductive sequence, starting from universal principles and deriving concrete actions from them. It is inductive, sorting out the concrete particulars in relation to the universal categories. The universal sheds light on the particular; the particular gives concreteness to the universal. There is constant movement between the two poles, each of which must be grasped in relation to the other, but the two poles are not equivalent or interchangeable.

To judge a community's moral thinking, then (one's own community or another), is not only to judge the adequacy of what it has understood; it is also to judge how that understanding has been converted into decision and action. It is attractive, and for some limited purposes persuasive, to presume that mutual approval at the level of principle is quite enough. Discrepancies of behaviour can then be treated lightly as unfortunate accidents that may sometimes befall generally sound principles. And there are times when this understanding of the situation is perfectly justified. A concrete act that gives offence has been produced, as all acts are, by a unique combination of historical contingencies. This act may therefore be out of line, unrepresentative of its agent's moral purposes and views. When one puts a foot wrong, there are many wrong places to put it. One can misinterpret the circumstances, misread others' intentions, misjudge the effects of one's own acts, assume a misplaced sense of responsibility. One can even (or so it has been thought since Aristotle) go wrong for no other reason than 'weakness'. At all events, there are failures of wisdom, charity, courage and prudence in practice which do not demonstrate failures of moral principle, character or purpose. Naturally, such a view is attractive in ecumenical contexts; it makes moral agreement seem attainable. Yet even if we are justified in saying that one robin doesn't make a winter, and that there may be true underlying harmony of conviction behind the occasional embarrassment or disgrace, we should not confuse true harmony of moral principle, character and purpose, with simple agreement on formulations of moral principle. Moral formulations are always to a degree conceptually underdetermined, requiring further interpretation in the concrete engagements of life, which alone will show how close the agreement really was.

Which is not to say that conceptual formulations are dispensible. It is impossible to do without the discussion of principles, and to judge one another solely by how we actually conduct ourselves. For unless we can reach a conceptual description to interpret the behaviour of the moment, we can never form a moral judgment on it. It is, in fact, a form of fanaticism - 'Cameronianism', perhaps, if we may borrow the name of the most uncompromising strand of the seventeenth century Scottish Covenanting movement - to assume that the whole character of an agent is manifest immediately in each and every concrete 
moment of action. Ignoring the complexity of the conditions of action, interpreting every act as having equally direct expressive force, it will always end up discovering universal and total incompatibilities of principle. The moment someone's action causes me offence, I conclude that it must spring from the principles on which he or she acts. Similarly, I interpret any communication with that person as springing from acquiescence in evil principles, any acquiescence as implying actual cooperation, any cooperation as implying equal responsibility, any responsibility for the least offence as implying responsibility for the greatest. Moral agreement is effectively ruled out apriori. That is why we must begin from such general conceptual agreements as were articulated by Life in Christ. They are the essential framework for pursuing agreement further: beyond generalities into specifics, beyond specifics into concrete practical demonstrations. But agreements that go no further than the general concepts will never achieve real moral harmony, since they will never address the offence given by types of behaviour and action.

We must speak, then, more specifically about moral offence, because this is how moral disagreement presents itself phenomenologically. It is the phenomenon of offence that creates the dynamic tendency that drives parties with moral disagreements always further apart. Moral wrongs, in act or thought, do not leave me simply unpersuaded; they leave me angry. Offence cannot merely be taken note of; it demands to be resented, disapproved of, and such disapproval to be signalled, at the very least, publicly. But disapproval then evokes self-justification and counter-disapproval; and so is set afoot the bad dynamic of self-redefinition, each side seeking to demonstrate, to itself and to the other, the sheer inevitability, and therefore the righteousness, of its anger. The only alternative to letting that dynamic take over is to cultivate a discipline of responding to offence immediately, by mutual questioning and explanation, by asking for reasons and offering them, by listening to them and challenging them. This discipline forces the critic to come to terms with how differently the offending deed may have looked from the point of view of the agent, and it forces the offending agent to go in search of explanations and answers that will genuinely satisfy the terms of the criticism. There can be no secure moral harmony without this discipline.

Moral offence arises, perhaps quite suddenly and unforeseen, demanding to be faced for what it is, not hidden behind the veil of difference and variation. The worst possible response to it is to pretend it is not there, and that there are 
only differences. Of course, there are many differences that are merely different - differences of practice, habit and expectation on which nothing of any ultimate moral importance hangs. It is highly desirable that in any two churches drawing closer together these innocuous differences should be much talked about, explained and recognised for what they are. But by the time offence has been given and taken, it is too late for that. Something is not merely different, but wrong; there has at least been a misunderstanding, which needs sorting out; there may have been more than a misunderstanding. That fact must first be acknowledged and addressed; otherwise it will sit lurking in the thievish corners of the streets and leap out to destroy the trust on which the developing relationship depends. ${ }^{14}$

Not only do acts give offence; ideas do, too. In a strongly discursive culture, where for every one thing we do we express a hundred opinions, it is more likely that offence will be given by something thought or said than by something done. Throughout the nineteenth century it could seem that disagreement at the level of moral ideas could coexist with harmonious social habits and practices and effective agreement on concrete judgments. Differing theories of Ethics competed to show that they could satisfactorily justify precisely the same concrete moral judgments, so that difference of ideas seemed innocuous, a playground for philosophers rather than a serious battlefield, but the experience of the twentieth century was quite different. And offensive ideas may still disturb even those who believe they have reached and enjoy agreement on fundamental principles. In any relationship other than between two people who know each other very deeply, we would be unwise to imagine that any disagreement that arises will always turn out to be of secondary importance. For agreement on general moral principles is only as secure as agreement on the more specific implications of those principles and their practical implementations. Disagreements which start small, can grow. Agreements can appear promising, and then unravel. The key to preventing these developments is to target the disagreements and to isolate them. That is why the kind of discursive exploration of moral concepts that Veritatis Splendor gave priority to is not something the churches can do without. Categorical moral claims must indeed be rooted in the New Testament, but they must be thought about and explored

14 I confess to some scepticism, therefore, as to the capacities of a policy of 'receptive ecumenism' and 'exchange of gifts', such as has been adopted by ARCIC III, to do justice to the perceptions of moral disagreement that still occupy their agenda. That is not to belittle the good that such an approach may do in other fields, or to deny that it may contribute usefully to preparing an environment for dealing with the questions of moral offence. But it does not deal with them. 
in their mutual implications and interpretations with a skilful deployment of the philosophical terms of art that moral tradition affords.

What would a head-on approach to the moral questions of our day which cause offence between Christian churches require of the various ministries of the church? The following sketch of the contributory strands of the moral discourse of the church is an ideal, yet it is close enough to how we actually conceive our various responsibilities to be at least a normative ideal, a model by which we can measure ourselves.

To begin with, it would involve a large role for the faithful laity, for the obvious reason that they have experience that is directly relevant to the questions in discussion. Living Christian discipleship is something that they do and its moral difficulties are difficulties that they can talk authoritatively about. This is true of common moral experiences: what it means, for example, to resist the temptation to accumulate wealth in a society where economic motivation is viewed as a primary incentive, is more likely to be understood by a lay Christian than a theologian, whose opportunities to accumulate wealth have probably been limited. But it is true also of specialist practices and callings. Bioethics, the ethics of defence, the ethics of education, cannot sensibly be thought about in the church without the voices of reflective Christian physicians, soldiers and teachers. What they have to contribute is not only descriptive information of the practices involved, but a witness to the moral intuitions that arise when those practices confront them with conscientious questions. Of course, specialist intuitions are not the only ones that count, for every specialist practice has to reckon with the validity of a view from outside, which sees things the practitioners do not see, as a well as a view from inside. Specialist experience is not a licence for members of the professions to erect barriers against questions or challenges from other Christians. Yet such experience cannot possibly be ignored, and least of all when it is part of a life of faith lived conscientiously within the fellowship of the church.

If we are to avoid the moral bankruptcy of trying to answer moral questions with sociological headcounts - a style that is too well known in the Anglican Communion by its strapline, 'Many Anglicans think ...' - a theological contribution to moral discussion is also essential. The catholic streams of Western Christianity have believed that well-formed faith is deeply implicated in a welllived life, and it is to the theologians that we look for a sense of the coherence of form that ties faith and life together. Their service involves making the moral tradition of the church, the continuity of the gospel in the life of past saints, available as a resource for contemporary deliberation, a task more difficult in many ways than interpreting the dogmatic tradition. Inevitably, contexts change from age to age, and each generation faces moral challenges in a form 
that has never quite arisen before. Sensitive interpretation of the moral tradition, avoiding both hagiographical narrative and stubborn refusal to learn from the past, requires a historical imagination of what particular deeds or thoughts of other generations meant to believers in their context. If, in the end, the contemporary church can make nothing of them, that is a failure of the theologians. And on them we depend, too, to encourage conceptual and dialectical clarity in moral discussion, safeguarding a proper integrity of philosophical discipline. One thing that the decades we have lived through show most clearly, I think, is that the greatest cause of moral fanaticism is inarticulacy and incoherence.

What, then, of the governing councils of the church and the bishops? On these we depend to make the discourse continually possible, nurturing and structuring occasions of serious moral engagement at every level of the church. Where there is actual moral disagreement, threatening the life of the church from within, they have the special task of ensuring that the particular conflict is seen within the wider perspectives of the church's moral teaching as a whole, structuring the most fruitful approaches to the problem, clarifying the grounds on which it may possibly be resolved, building on such resolutions as are reached. The demand of the present Archbishop of Canterbury that the church should learn to practise 'good disagreement' is an appropriately episcopal plea. But precisely in the pursuit of good disagreement, the bishops also have the task of articulating and confirming well-founded agreements, agreements which the church can claim to enjoy in fact. Learning 'good disagreement' is actually learning to agree. For learning to agree involves focusing on disagreements, achieving clarity about where precisely they lie, describing them with exactitude, narrowing them down to their core. That way we resist the twin temptations of allowing particular presenting disagreements to become so total that they become undiscussable and of suppressing them by treating disagreement as apriori unreal. Without good agreement, good disagreement is impossible, because disagreement appears vast and unlimited, occupying the whole horizon. It is the bishops' task to ensure that disagreements are focused, not infinitely expansive. But then, too, there is a further episcopal task: since the church's agreements belong of right to the world Christ came to save, they need to be addressed to the world. In moral discourse, too, there is a proclamatory and missionary role for the bishops to assume.

Our question about Anglican-Roman Catholic moral disagreement proves more complicated and wide-ranging than it first looked to be, but there is great value in allowing its complications to unfold. Instead of appearing merely as a housekeeping matter about about the church's own good order, it points us outward to the apostolic mission to the world. If the churches could do no 
more than model mutual questioning and accounting over matters of mutual offence, they might offer a startling and highly regenerative witness to a culture in which the capacity for any kind of discourse seems to be failing. The gospel calls on the world to repent, and so it should, for there are many practices and assumptions in public affairs that require radical change of mind. But conscientious change of mind requires conscientious discourse to reach it. The sudden seismic reversals of conviction that have taken to sweeping across Western society without without warning or forethought are not effective exercises of public conscience; they witness precisely to the lack of a discursive context in which an informed conscience can emerge. Spasmodic self-reinvention never generates freedom, and inarticulacy is inevitably enslaving. The ministry of the church to a civilisation that is addicted to such epileptic moral seizures is surely to model, in faithfulness to Christ, what articulate and humane discussion of agreement and disagreement should look like. ${ }^{15}$

15 At the time of writing we still await the publication of the results of the Church of England's 'Living in Love and Faith' project, which has aimed to 'produce resources that will help the Church to learn how questions about human identity, relationships, marriage and sexuality fit within the bigger picture of what it means to embody a Christian vision of living holy lives in love and faith in our culture' (churchofengland.org/LLF). Any comment on its design, procedure or long-term strategy would be premature. It should be said, however, that its appreciation of the scope within which a long-running cause of offence within the church needs to be addressed is a sign of hope. 